\title{
Modified stabilization method for the tibial tuberosity advancement technique: a biomechanical study
}

\author{
Modificação da técnica de avanço da tuberosidade tibial: estudo biomecânico \\ Bruno Testoni Lins ${ }^{\mathrm{I}, \mathrm{II}^{*}}$ Sheila Canevese Rahal ${ }^{\mathrm{I}}$ Mário Jefferson Louzada ${ }^{\mathrm{III}}$ \\ José Carlos Dalmas ${ }^{\mathrm{IV}}$ André Luis Selmi ${ }^{\mathrm{II}}$
}

\begin{abstract}
The present study aimed to determine biomechanical alterations resultant from a modification in the fixation method of the tibial tuberosity advancement technique (TTA), originally described for stabilization of the cranial cruciate-deficient stifle. Ten adult mongrel dogs weighing 25$30 \mathrm{~kg}$ were used. After euthanasia, performed for reasons unrelated to this study, the hind limbs were distributed into two groups: $G 1$ operated $(n=10)$ and $G 2$ control $(n=10)$, represented by the contralateral limb. The operated hind limbs were orthopedically, goniometrically and radiographically evaluated, sequentially at four moments: moment 1 , in intact joints; moment 2, after cranial cruciate desmotomy; moment 3 , after surgical stabilization of the stifle joint using modified TTA; and moment 4, after caudal cruciate ligament desmotomy. The tibial tuberosity was stabilized by one shaft screw craniocaudally and a titanium cage inserted at the osteotomy site. The position of the patellar tendon at $90^{\circ}$ in relation to the tibial plateau allowed cranial tibial thrust force neutralization, despite cranial drawer motion maintenance in all dogs. The biomechanical tests confirm the viability of the tibial tuberosity fixation method and support future clinical trials to validate the technique.
\end{abstract}

Key words: tibial tuberosity advancement, cranial cruciate rupture, biomechanics.

\section{RESUMO}

O presente estudo teve como objetivo determinar as alterações biomecânicas decorrentes da modificação da técnica de avanço da tuberosidade tibial (TTA), originalmente descrita para estabilização da ruptura do ligamento cruzado cranial. Foram avaliados 10 cães, sem raça definida e com peso entre 25 e $30 \mathrm{~kg}$, submetidos à eutanásia por razões independentes do presente estudo. Os membros pélvicos foram distribuídos em dois grupos: G1 operado $(n=10)$ e $G 2$ controle $(n=10)$, representado pelo membro contralateral. Os membros operados foram submetidos à avaliação ortopédica, goniométrica e radiográfica nos momentos 1 (articulação intacta), 2 (após desmotomia do cruzado cranial), 3 (após estabilização articular pela TTA modificada) e 4 (após a desmotomia do cruzado caudal). A tuberosidade tibial foi estabilizada por um parafuso cortical em posicionamento craniocaudal e um espaçador de titânio inserido no local de osteotomia. A posição do tendão patelar perpendicular em relação ao platô tibial promoveu a neutralização da força de cisalhamento tibial cranial, apesar da permanência do movimento de gaveta cranial em todos os joelhos. Os testes biomecânicos confirmam a viabilidade do método empregado para estabilização da tuberosidade tibial e sustentam a realização de estudos clínicos futuros para validação da técnica.

Palavras-chave: avanço da tuberosidade tibial, ruptura do ligamento cruzado cranial, biomecânica.

\section{INTRODUCTION}

The instability and degenerative joint disease caused by cranial cruciate ligament (CCL) rupture are well defined as frequent causes of pain and lameness of hind limbs in dogs (CONZEMIUS et al.,

'Departamento de Cirurgia e Anestesiologia Veterinária, Faculdade de Medicina Veterinária e Zootecnia (FMVZ), Universidade Estadual Paulista (Unesp), Botucatu, SP, Brasil.

"Escola de Medicina Veterinária, Universidade Anhembi Morumbi. Rua Conselheiro Lafaiete, 64, Brás, 03113-064, São Paulo, SP, Brasil. E-mail: bt_lins@yahoo.com.br. Autor para correspondência.

II'Departamento de Produção e Saúde Animal, Unesp, Botucatu, SP, Brasil.

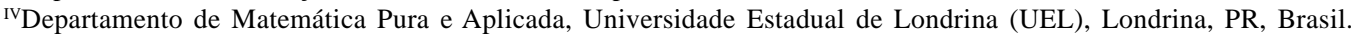


2005). The development of surgical procedures that promote changes in joint anatomy and biomechanics constitutes a new perspective to decrease osteoarthrosis progression and restore normal limb function (MONTAVON et al., 2002). The Tibial Plateau Leveling Osteotomy (TPLO) has been studied and used worldwide, especially in the United States and Europe, with promising results (WARZEE et al., 2001; BALLAGAS et al., 2004; CONZEMIUS et al., 2005). Although cranial drawer movement is not eliminated, TPLO leads to the functional stability of the stifle joint during the stance phase of locomotion (REIF et al., 2002; BALLAGAS et al., 2004). Despite the overall acceptance by most surgeons, studies using force plate analysis showed similar results in long-term outcome from the lateral suture technique and the Slocum TPLO (BALLAGAS et al., 2004; CONZEMIUS et al., 2005).

Tibial Tuberosity Advancement (TTA) was described as a new alternative for stabilization of the cranial cruciate deficient stifle. According to the authors, the method promotes less alteration to the intraarticular and periarticular components, and therefore leads to superior clinical results (TEPIC, 2006). The technique is based on comprehension of the internal and external forces acting on the stifle joint (GUERRERO, 2003; HOFFMAN et al., 2007). The contraction of the quadriceps and flexor muscle in the original joint results in a force whose vector is approximately parallel to the patellar tendon and cranially sloped in relation to the tibial plateau (MONTAVON et al., 2002; INNES, 2006). The biomechanical principle of the method consists of the neutralization of the cranial tibial thrust force by placement of the patellar tendon perpendicular to the tibial plateau (TEPIC, 2006; MILLER et al., 2007). The new position is achieved by osteotomy of the tibial tuberosity and insertion of a spacing cage in the defect, followed by stabilization with a special titanium plate fixed by fork and screws. It is necessary to emphasize however, that like Slocum's TPLO both specialized training and acquisition of specific instruments are needed to perform TTA (MONTAVON et al., 2002). Despite the theory behind the technique, there are few reports about the exact biomechanical modifications after TTA on the stifle joint (APELT et al., 2007; HOFFMANN et al., 2006; MILLER et al., 2007).

The present study evaluated, ex vivo, a modification method for stabilization of the tibial tuberosity advancement technique using a spacing cage inserted at the osteotomy site and a stainless steel shaft screw positioned in a craniocaudal direction from the tibial tuberosity. The hypothesis is that modified Tibial Tuberosity Advancement converts cranial tibial thrust into a caudally directed force similar to the traditional technique.

\section{MATERIALS AND METHODS}

Animals and experimentation groups

The methods used during the development of the present study were approved by the Ethics Committee for Animal Experimentation of the School of Veterinary Medicine and Animal Science, Sao Paulo State University (Unesp-Botucatu). Ten male mongrel dogs, aged between 1.8 and 4.2 years (mean $=3$ years) and weighing $20-30 \mathrm{~kg}$ ( mean $=27.8 \mathrm{~kg}$ ), euthanatized for reasons unrelated to this study and free of orthopedic disorders, were studied. Immediately after euthanasia, the limbs were numbered 1 to 10 , according to the respective dog, and randomly divided into two groups: G1 operated ( $\mathrm{n}=10)$, and G2 control, that is, not operated $(n=10)$ represented by the opposite limb. All dogs included in the present study had tibial plateau angles between 20 and 28 degrees.

\section{Experimental moments of Group 1}

The surgical procedures performed on Group 1 were divided into four experimental moments, according to a sequential order: at moment 1 the CCL was maintained intact and two cortical screws $(3.5 \mathrm{~mm}$ in diameter and $12 \mathrm{~mm}$ in length) were inserted at the origin and insertion of the medial collateral ligament to serve as radiopaque markers; at moment 2 , transection of the CCL was performed after a medial parapatellar arthrotomy, and at moment 3 the lesion was corrected by a modified TTA technique; finally, at moment 4 , transection of the caudal cruciate desmotomy was performed via a medial arthrotomy.

Pre-operative plan and surgical procedure

To perform the surgery, the distance of the tibial tuberosity advancement was determined radiographically, after transection of the cranial cruciate ligament, in the mediolateral $x$-ray projection with the stifle at $140^{\circ}$ extension. The patellar tendon was represented by a line from the distal patella to the proximal tibial tuberosity and the tibial slope determined by a line tangent to the cruciate ligament insertion points. The angle formed between the two lines determined the patellar tendon inclination. An acetate sheet with perpendicular lines in predetermined scale was laid up over the radiography using the patellar tendon and tibial plateau marks to determine the spacing cage size (MONTAVON et al., 2002).

The dog was placed in dorsal recumbence, slightly rotated to one side to allow a medial approach 
to the proximal half of the tibia. Afterwards, the tibial tuberosity was freed from soft tissue and a longitudinal osteotomy performed with an electric oscillating saw. The osteotomy started at the point between the tibial shaft and tuberosity and was directed proximally to a point cranial to the meniscus borders, avoiding the patellar tendon. An osteotome with width similar to the spacing cage was inserted at the osteotomy site to promote cranial and proximal translation of the tibial tuberosity. The previously determined spacing cage was inserted at the osteotomy site and fixed cranially and caudally with two self-tapping titanium screws (3.5mm in diameter), one in the tibial tuberosity and the other in the caudal segment of the proximal tibia. The tibial tuberosity was stabilized with a stainless steel shaft screw (4mm in diameter) inserted distally to the spacing cage and oriented in a craniocaudal direction (Figure1). To avoid iatrogenic fracture of the tibial tuberosity during hole drilling from the tibial tuberosity to the caudal cortex of the proximal portion of the tibia, drill bit sizes were sequentially increased $1.5-3.5 \mathrm{~mm}$ in diameter. The drill hole was measured with a depthgauge and an appropriate self-tapping screw inserted in lag fashion. Finally, transection of the semitendinous muscle tendon was performed to allow coverage of implants and bone defect, similarly to the technique originally described by MONTAVON et al. (2002). The crural fascia was closed with a simple interrupted suture, the subcutaneous by a simple continuous suture and skin using simple interrupted suture.

\section{Evaluation methods}

Orthopedic evaluation. The orthopedic examination was performed with the animal in lateral recumbence. It included the cranial and caudal drawer tests, tibial compression test, digital pressure on patella to elicit lateral or medial displacement and visual inspection of bone alignment.

Goniometric evaluation. The range of motion of the stifle joint was elicited by determination of maximal flexion and extension angles using a goniometer according to the technique described by MILLIS et al. (2004).

Radiographic evaluation. Radiographic evaluation of the hind limbs was performed, in mediolateral neutral and stressed projections with the dog in lateral recumbence at the end of the each moment, on Group 1. The neutral mediolateral projection was held with the stifle extended $140^{\circ}$ to determine the patellar tendon angle. The stressed mediolateral view was taken by positioning the stifle and hock at flexion of $90^{\circ}$ for determination of the tibial plateau angle, quantification of the tibial subluxation in relation to the femur and evaluation of patellar position in the troclear groove. Also, caudocranial projections were made, with the dog in dorsal recumbence, to exclude bone deformities and confirm the correct placement of implants.

To quantify the tibial displacement in relation to the femur in the sagittal plane, the horizontal distance $\left(\mathrm{x}_{\mathrm{i}}\right)$ was measured between the tibial markers and the intersection line in the femur marker in the stressed view. The tibial displacement $\left(\mathrm{S}_{\mathrm{i}}\right)$ was computed by using the formula $S_{i}=x_{i}-x_{0}$, with $x_{0}$ defined as the horizontal distance between femur and tibial markers at moment 1 and $\mathrm{x}_{\mathrm{i}}$ the distance at each sequential moment (WARZEE et al. 2001).

\section{Statistical analysis}

The statistical analysis was performed using the non-parametric Friedman test to determine the differences in flexion, extension and range of motion between the moments $1,2,3$ and 4 . The Student's t test was used to compare differences between values of cranial and caudal tibial displacement. Pearson's coefficient test was used to check whether patellar and tibial plateau angles were correlated. All data were considered significant if $\mathrm{P}<0.05$.

Ciência Rural, v.39, n.2, mar-abr, 2009. 


\section{RESULTS}

After desmotomy of the CCL, all stifles $(n=10)$ presented positive cranial drawer and tibial compression tests. After the modified TTA, the cranial drawer test was still positive in all dogs, whereas a negative tibial compression test was observed in nine stifles. The only stifle with a positive tibial compression test was determined to have a displacement of a lesser magnitude than after transection of the cranial cruciate ligament. After caudal cruciate ligament transection, cranial drawer movement became more accentuated, but tibial compression test was kept similar to the moment after the modified TTA was employed. Patellar luxation or distal displacement of patella in the trochlear groove was not observed at any of the evaluation moments. At moment 3 there were no differences in range of motion between the intact stifle joint and after modified TTA.

The values for patellar tendon inclination were similar between the operated group at moment 1 $\left(102.0^{\circ} \pm 4.83^{\circ}\right)$ and the control group $\left(104.5^{\circ} \pm 4.97^{\circ}\right)$. There was no correlation between patellar tendon and tibial plateau angle. After CCL desmotomy, the mean cranial tibial subluxation observed via stressed radiography was $13.7 \mathrm{~mm}$. After modified TTA the cranial subluxation was significantly reduced (mean of $1.7 \mathrm{~mm}$ ), with four stifles presenting complete joint stability, five with reduced cranial tibial subluxation (1$3 \mathrm{~mm}$ ) and only one joint with accentuated cranial subluxation (7mm) (Figure 2). The caudal cruciate ligament transection resulted in a mean caudal tibial subluxation of $2.8 \mathrm{~mm}$.

\section{DISCUSSION}

The present study demonstrated that tibial tuberosity advancement converts a cranial tibial thrust into a caudal force despite cranial cruciate ligament injury. The determination of the patellar tendon angle was fundamental for planning the method used in the present study. The surgical goal is to advance the tibial tuberosity by a predetermined distance and in this manner turn the patellar tendon perpendicular to the tibial plateau and parallel to the tibial diaphysis, thus neutralizing the cranial tibial thrust force (TEPIC, 2006; HOFFMANN et al., 2006). It is necessary to maintain a joint extension angle of $140^{\circ}$ during radiographs, because the placement of the stifle joint in slight flexion probably will result in underestimation of the patellar tendon angle (GUERRERO, 2003) and therefore, application of a space cage shorter than the ideal. In this manner, the patellar tendon angle will be greater than $90^{\circ}$ and the cranial tibial thrust force will not be neutralized, resulting in joint instability (MONTAVON et al., 2002).

The adequate radiographic positioning is confirmed by the similar patellar tendon angles among the seven limbs of around $100^{\circ}$ before and after the CCL desmotomy. In the other three specimens, a small difference was verified, with underestimation between angles at moments 1 (CCL intact) and 2 (After CCL desmotomy). In limbs 1 and 5 the angles were, respectively, $105^{\circ}$ and $100^{\circ}$ at moment 1 versus $100^{\circ}$

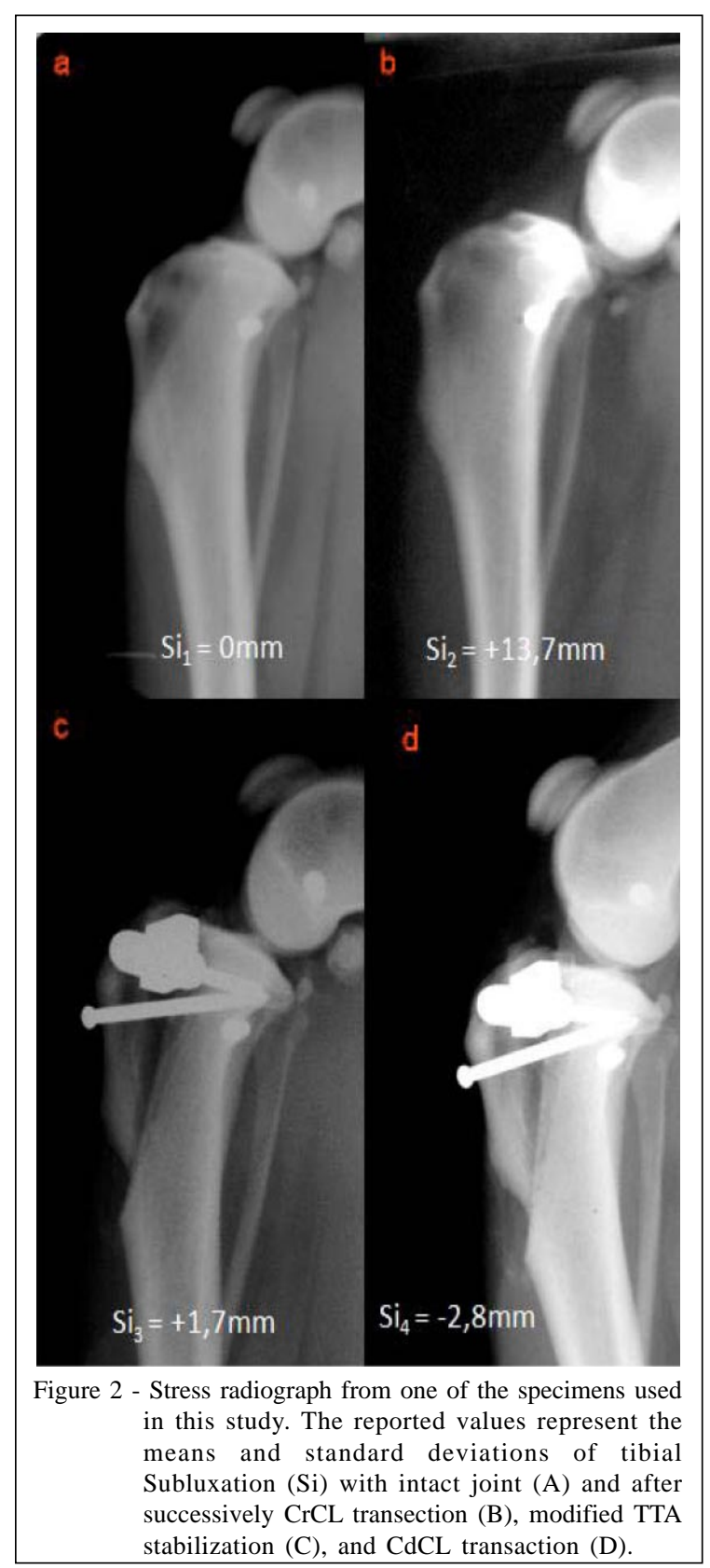

Ciência Rural, v.39, n.2, mar-abr, 2009. 
and $95^{\circ}$ at moment 2 , and in limb 3 the angle was $115^{\circ}$ at moment 1 and $105^{\circ}$ at moment 2 . These small variations can be considered normal and are in accord with the literature (HOFFMAN et al. 2007).

The proposed modification in the technique was the replacement of the titanium plate and fork by one stainless steel screw, but with maintenance of a special spacing cage. Although much simpler than the original technique, the proposed modification requires special considerations. In the original TTA, the authors preclude the osteotomy in two steps to maintain bone alignment (GUERRERO, 2003). Initially, the distal osteotomy is performed, and after partial plate fixation, the osteotomy is completed in a proximal direction (MONTAVON et al., 2002). Under the proposed alternative fixation system, according to the characteristics of implants, a one-step procedure for the osteotomy seems necessary. The use of a bone clamp to temporarily stabilize the tibial tuberosity, during drilling and insertion of the craniocaudal screw allowed for maintenance of correct bone alignment. Also, to prevent iatrogenic fracture or fissure of the tibial tuberosity, the craniocaudal hole was drilled with progressively increasing bit diameters. This strategy permitted good results, since none of the limbs presented any sign of bone lesion during screw insertion. However this can be a challenge in small dogs due to increased risk of tibial tuberosity fissures during hole perforation.

The perpendicular angle of the patellar tendon after tibial tuberosity advancement (moment 3 ) was confirmed by radiographic exam in seven of 10 dogs evaluated in the present study (TEPIC, 2006; HOFFMANN et al., 2006). The other three dogs had an excessive reduction of the patellar tendon, with angles between $86^{\circ}$ and $88^{\circ}$. All limbs had a positive cranial drawer sign and negative compression test. This observation is in accordance with the biomechanical principle of dynamical joint stabilization provided by the TTA technique (MONTAVON et al., 2002). Despite no evidence of instability during the orthopedic exam, the stressed radiographies revealed in five limbs, cranial tibial subluxations between 1 and $3 \mathrm{~mm}$. These values agree with other authors who described mean craniocaudal instability of $7.3 \mathrm{~mm}$ in limbs tested in a special apparatus simulating the weight sustaining phase of locomotion (FALCIS et al. 2006). This residual instability is attributed to the character of the study using cadavers. The cranial tibial thrust force is minimized by the balance between the quadriceps muscle group and the flexor mechanism, and the stability is dependent upon the full action of these muscles during locomotion (FALCIS et al., 2006;
HOFFMANN et al., 2006; MILLER et al., 2007). Dog 3 had an excessive tibial subluxation of $7 \mathrm{~mm}$ attributed to a sloped tibial plateau of $28^{\circ}$ (VEZZONI, 2006).

After desmotomy of the caudal cruciate (moment 4), in all stifles an increase in the degree of instability in comparison to moment 3 was verified (joint stabilization by the modified TTA technique), as a result of the caudal drawer movement. The evaluation of the stressed radiography confirmed caudal tibial subluxation $(2.8 \pm 1.2 \mathrm{~mm})$, indicating transformation of the cranial tibial thrust into a caudal component. According to some authors, the magnitude of transformation of the cranial tibial thrust force is directly proportional to the amount of cranial displacement of the tibial tuberosity (APELT et al., 2007). This observation highlights the necessity for other studies to determine the ideal distance for tibial tuberosity advancement and the effects of excessive reduction on caudal cruciate ligament and other joint components (REIF et al. 2002; TEPIC, 2006; MILLER et al., 2007).

\section{CONCLUSION}

The modified tibial tuberosity advancement technique was effective in neutralizing the cranial tibial thrust force after cranial cruciate desmotomy. The biomechanical tests confirmed the viability of the method used for stabilization of the tibia tuberosity and support future clinical trials to validate the technique.

\section{ACKNOWLEDGMENT}

To Fundação de Apoio à Pesquisa do Estado de São Paulo (FAPESP) for providing Bruno Lins Master's Grant (10951-3) and to Tuktor Orthopedic implants.

\section{ETHICAL COMMITTEE AND BIOSECURITY}

The methods used during the development of the present study were approved by the Ethical Committee for Animal Experimentation of the School of Veterinary Medicine and Animal Science, São Paulo State University (UNESP Botucatu) (Protocol number 109/2004).

\section{REFERENCES}

APELT D. et al. Effect of tibial tuberosity advancement on cranial tibial subluxation in canine cranial cruciate-deficient stifle joints: an in vitro experimental study. Veterinary Surgery, v.36, n.2, p.170-177, 2007.

BALLAGAS, A.J. et al. Pre- and postoperative force plate analysis of dogs with experimentally transected cranial cruciate ligaments treated using tibial plateau leveling osteotomy. Veterinary Surgery, v.33, n.2, p.187-190, 2004. 
CONZEMIUS, M.G. et al. Effect of surgical technique on limb function after surgery for rupture of the cranial cruciate ligament in dogs. Journal of the American Veterinary Medical Association, v.226, n.2, p.232-236, 2005.

FALCIS, C.C., et al. Effect of tibial tuberosity advancement on passive joint kinematics in the cranial cruciate ligament deficient canine stifle. In: WORLD VETERINARY ORTHOPEDIC CONGRESS, 2.; ANNUAL VETERINARY ORTHOPEDIC SOCIETy MEeting, 33., 2006, Keystone. Proceeding... Keystone: Veterinary Orthopedic Society, 2006. p.172.

GUERRERO, T.G. Advancement of the tibial tuberosity for the treatment of cranial cruciate deficient canine stifle. 2003. (Vídeo film). Thesis (PhD in Small Animal Surgery) - Vetsuisse Faculty, University of Zurich, Zurich.

HOFFMANN, D.E. et al. Tibial tuberosity advancement in 65 canine stifles. Veterinary and Comparative Orthopedics and Traumatology, v.19, n.4, p. 219-227, 2006.

INNES, J.F. Etiopathogenesis of canine cruciate disease. In: WORLD VETERINARY ORTHOPEDIC CONGRESS, 2.; ANNUAL VETERINARY ORTHOPEDIC SOCIETY MEEting, 33., 2006, Keystone. Proceeding... Keystone: Veterinary Orthopedic Society, 2006. p.39-41.

MILLER, J.M. et al. Effect of $9 \mathrm{~mm}$ tibial tuberosity advancement on cranial tibial translation in the canine cranial cruciate ligament-deficient stifle. Veterinary Surgery, v.36, n.4, p.335-340, 2007.
MILLIS, D.L. et al. Orthopedic and neurologic evaluation. In: MILLIS, D.L. et al. Canine rehabilitation \& physical therapy. Philadelphia: Saunders. 2004. Cap.10, p.179-200.

MONTAVON, P.M. et al. Advancement of the tibial tuberosity for the treatment of cranial cruciate deficient canine stifle. In: WORLD VETERINARY ORTHOPEDIC CONGRESS, 2002, Keystone. Proceeding... Keystone: Veterinary Orthopedic Society, 2002. p.39-41.

REIF, U. et al. Effect of tibial plateau leveling on stability of the canine cranial cruciate deficient stifle joint. An in vitro study. Veterinary Surgery, v.31, n.2, p.147-154, 2002.

TEPIC, T. Cranial tibial tuberosity advancement for the cruciate deficient stifle. In: WORLD VETERINARY ORTHOPEDIC CONGRESS, 2.; ANNUAL VETERINARY ORTHOPEDIC Society MeEting, 33., 2006, Keystone. Proceeding... Keystone: Veterinary Orthopedic Society, 2006. p.44-45.

VEZZONI, A. Comparison of tibial plateau leveling osteotomy and tibial tuberosity advancement. In: WORLD VETERINARY ORTHOPEDIC CONGRESS, 2.; ANNUAL VETERINARY ORTHOPEDIC SOCIETY MEETING, 33., 2006, Keystone. Proceeding... Keystone: Veterinary Orthopedic Society, 2006. p.47-48.

WARZEE, C.C. et al. Effect of tibial plateau leveling on cranial and caudal tibial thrusts in canine cranial cruciate ligamentdeficient stifles: An in vitro experimental study. Veterinary Surgery, v.30, n.3, p.278-286, 2001. 